Systematic Review

\title{
Prevalence of Recurrent Herniation Following Percutaneous Endoscopic Lumbar Discectomy: A Meta-Analysis
}

Si Yin, MD, Heng Du, MD, Weizhou Yang, MD, Chungguang Duan, PhD, Chaoshuai Feng, MD, and Huiren Tao, MD

From: First Affiliated Hospital of Xi'an Jiaotong University, China

Address Correspondence: Huiren Tao, MD Department of Orthopaedic Surgery, First Affiliated Hospital of Xi'an Jiaotong University Room 1501, Inpatient Building No. 277 Road Yantawest Xi'an, China

E-mail: taohuiren@126.com

Disclaimer: This study was supported by the Natural Science Foundation of Shaanxi Province of China (grant number 2015SF-199). Conflict of interest:

Each author certifies that he or she, or a member of his or her immediate family, has no commercial association (i.e., consultancies, stock ownership, equity interest, patent/licensing arrangements, etc.) that might pose a conflict of interest in connection with the submitted manuscript.

Manuscript received: 10-04-2017 Revised manuscript received: 02-28-2018

Accepted for publication: 03-06-2018

Free full manuscript: www.painphysicianjournal.com
Background: Percutaneous endoscopic lumbar discectomy (PELD) is a minimally invasive surgery for the treatment of lumbar disc herniation (LDH) with a smaller incision, decreased damage to soft tissues, faster recovery, and fewer postoperative complications. However, the exactly epidemiological prevalence of recurrent herniation after PELD remains unclear.

Objectives: To investigate the epidemiological prevalence of recurrent herniation in patients following PELD and to analyze the potentially related risk factors.

Study Design: Meta-analysis and systematic review of prospective and retrospective studies.

Methods: We conducted a comprehensive search in MEDLINE, EMBASE, and Cochrane Central Register of Controlled Trials that mentioned the incidence of recurrent herniation after PELD. The overall prevalence estimate was calculated by an appropriate meta-analysis. Subgroup analysis, sensitivity analysis, and publication bias assessment were also performed in our study, respectively.

Results: Our results showed the overall prevalence of recurrent herniation after PELD was 3.6\% (95\% Cl 3.0-4.3\%). The prevalence estimates after percutaneous endoscopic interlaminar discectomy (PEID) and percutaneous endoscopic transforaminal discectomy (PETD) were $4.2 \%$ and $3.4 \%$, respectively. Individuals with older age ( $\geq 50$ years) and higher BMI $(\geq 25)$ had increased recurrence rates after PELD than those with younger age (4.3\% vs. $2.7 \%$ ) and normal body mass index (BMI) (4.8\% vs. 1.5\%). The prevalence was significantly higher at upper discs $(5.4 \%)$ than that at L4-5 (2.7\%) and L5-S1 (3.1\%) level. The incidence of recurrent herniation at lateral disc was $4.7 \%$, and the recurrence rate of migrated herniation was $3.8 \%$. In most cases, the recurrent herniation occurred within 6 months postoperatively (accounting for $61.7 \%$ ).

Limitations: A majority of the included articles were relatively low quality retrospective studies with significant heterogeneity among them. Furthermore, owing to the paucity of data focused on recurrence, many potentially predictive factors related to subgroup analyses could not be conducted, which might have influenced the accuracy and comprehensiveness of our meta-analysis.

Conclusions: PELD is associated with a certain rate of recurrence (3.6\%), which usually occurred within 6 months postoperatively. Older age ( $\geq 50$ years), obesity (BMI $\geq 25$ ), upper lumbar disc and central disc herniation might be independent risk factors for recurrence after PELD; however, different surgical approaches (PETD or PEID), lateral discs, migrated discs and foraminoplasty did not affect the incidence. These factors could be useful in preoperative evaluation, appropriate patient selection and informed consent before PELD.

Key words: Percutaneous endoscopic lumbar discectomy, prevalence, recurrent herniation, meta-analysis

Pain Physician 2018: 21:337-350 
P ercutaneous endoscopic lumbar discectomy (PELD) is a minimally invasive surgery for the treatment of lumbar disc herniation (LDH) and has been increasingly used for more than 20 years. Numerous clinical studies have confirmed that PELD has similar effectiveness to conventional surgery and has obvious advantages such as smaller incisions, decreased damage to soft tissues, faster recovery, and fewer postoperative complications (1-2). However, along with the widespread use of the procedure, the recurrent herniation after PELD has become an issue of concern for researchers and surgeons (3). The recurrence rate after successful PELD is reported at 0 to $12.5 \%$, showing a significant range, with many studies focused on the risk factors causing recurrent herniated lumbar disc (4-5). Some of the most often mentioned risk factors for recurrence are age at the time of surgery, gender, obesity, herniation type, location of herniation, surgical approach, and learning curve of the surgeon (6-7).

Up to now, there has been a lack of a recognized uniform understanding about etiology, pathomechanism and even epidemiological assessment of the recurrent herniation after successful PELD. To the best of our knowledge, no studies have been conducted by metaanalysis regarding the epidemiological prevalence of recurrent herniation after PELD. Therefore, the purpose of the present study is to review the related literature referring to the recurrent herniation after PELD and to investigate its prevalence and related risk factors, in attempt to provide available detailed evidence-based data for preoperative evaluation, appropriate patient selection and informed consent.

\section{Methods}

\section{Search Strategy and Eligibility Criteria}

Through an electronic search and independent, manual searches by 2 clinical librarians (SY and WY), we identified all qualified articles that referred to the incidence of recurrent herniation after PELD in all languages up to August 2017. The sources of electronic searching include MEDLINE, EMBASE, and The Cochrane Central Register of Controlled Trials. The following key terms were included in our searches: "percutaneous endoscopic lumbar discectomy," "percutaneous endoscopic transforaminal discectomy," "percutaneous endoscopic interlaminar discectomy," "transforaminal lumbar discectomy," "transforaminal full-endoscopic lumbar discectomy," "recurrent herniation," "recurrence," and "recurrent rate." Additionally, bibliographies of all selected full text articles were reviewed to identify more articles. Two reviewers (SY and WY) independently checked the titles and abstracts of all articles identified from the database. The full texts of all potentially relevant studies were also assessed by 2 reviewers if necessary. If no agreement could be reached, a third reviewer $(\mathrm{HT})$ made the final decision.

The eligibility criteria of the included articles were: 1) those that mentioned the incidence of recurrent herniation after primary PELD for the treatment of LDH; 2) a retrospective study, prospective study, cohort study, regardless of sample size; 3 ) sufficient reported data for extraction and calculation of a recurrence rate with $95 \%$ confidential interval $(\mathrm{Cl})$; 4) patients were followed up for at least 6 months; 5 ) in the case of duplicate publication, the most recent or largest study was selected; 6) publications were excluded if the patients underwent PELD as revision procedures, and publications were also excluded if they were review articles, comments, case reports, letters, animal trials, or cadaver studies; 7) No restriction related to the languages was defined.

\section{Data Extraction}

Two reviewers (SY and CF) independently extracted the data of included studies and reached consensus on each item. Data included: 1) authors' names and nationality, language, publication time, study design, recruitment period, follow-up time, and journal title of each included study; 2 ) sample size and patient's demographic characteristics including age, gender, body mass index (BMI); 3) recurrence case number, recurrence time and other details; 4) the location, type and level of herniated disc; 5) proportion of surgical type including percutaneous endoscopic transforaminal discectomy (PETD), percutaneous endoscopic interlaminar discectomy (PEID), with or without additional procedures such as foraminoplasty, annular sealing, etc. Recurrence was defined as disc herniation on the same side and level as the primary operative site after successful initial removal of the protruding disc and a pain-free interval after operation, which was revealed on an immediate postoperative MRI (6). In addition, recurrence was classified according to time period, with early recurrence at less than 6 months and late recurrence at $>6$ months postsurgical intervention (8).

\section{Assessment of Heterogeneity and Publication Bias}

The heterogeneity was assessed by using Cochran's Chi square-based $Q$ statistic and $I^{2}$ test $\left(I^{2}=0-25 \%\right.$ 
represents no heterogeneity; $\mathrm{I}^{2}=25-50 \%$ represents moderate heterogeneity; $1^{2}=50-75 \%$ represents large heterogeneity; $I^{2}=75-100 \%$ represents extreme heterogeneity) (9-10). The value of $\mathrm{I}^{2}$ greater than $50 \%$ would be considered substantial heterogeneity. A sensitivity analysis was performed for the measured effects by omitting the studies which may largely influence the clinical results (11). In addition, potential publication bias was assessed using funnel plot and Egger's regression test for all included studies and each subgroup analysis (12).

\section{Statistical Analysis}

We conducted a meta-analysis using STATA package version 12.0 program (StataCorp, College Station, TX, USA) for all extracted data. When a significant $Q$ test $(P<0.10)$ or $I^{2}>50 \%$ indicated heterogeneity across studies, the Dersimonian and Laird method random effects model was used for meta-analysis, otherwise the Mantel-Haenszel method fixed effects model was used. Based on this, we calculated the point prevalence of recurrent herniation after PELD with its $95 \% \mathrm{Cl}$ for each individual study, and then a pooled prevalence estimate and $95 \% \mathrm{Cl}$ were generated. We also performed subgroup analysis based on surgical procedure (PETD and PEID), age ( $<50$ and $\geq 50$ years), BMI ( $<25$ and $\geq 25$ ), level of herniated disc (upper discs, L4-5 and L5-S1), location of herniated disc (central, paramedian and lateral), type of herniated disc (migrated and non-migrated), recurrence time ( $<6$ months and $>6$ months), and with or without additional procedures such as foraminoplasty. Sensitivity analysis was conducted to evaluate the influence of excluding prospective studies, excluding studies with total patients $<50$ and $<$ 500 , and excluding studies with period of follow-up less than 12 months, respectively. All statistic tests performed in this study were 2-tailed, and $P<0.05$ was taken as being statistically significant.

\section{Results}

\section{Characteristics of Included Studies}

After applying the search strings, we identified 576 potentially eligible articles. Of the 576 articles, 224 were duplicates (Fig. 1). One hundred and sixty-one articles were excluded based on their titles and abstracts

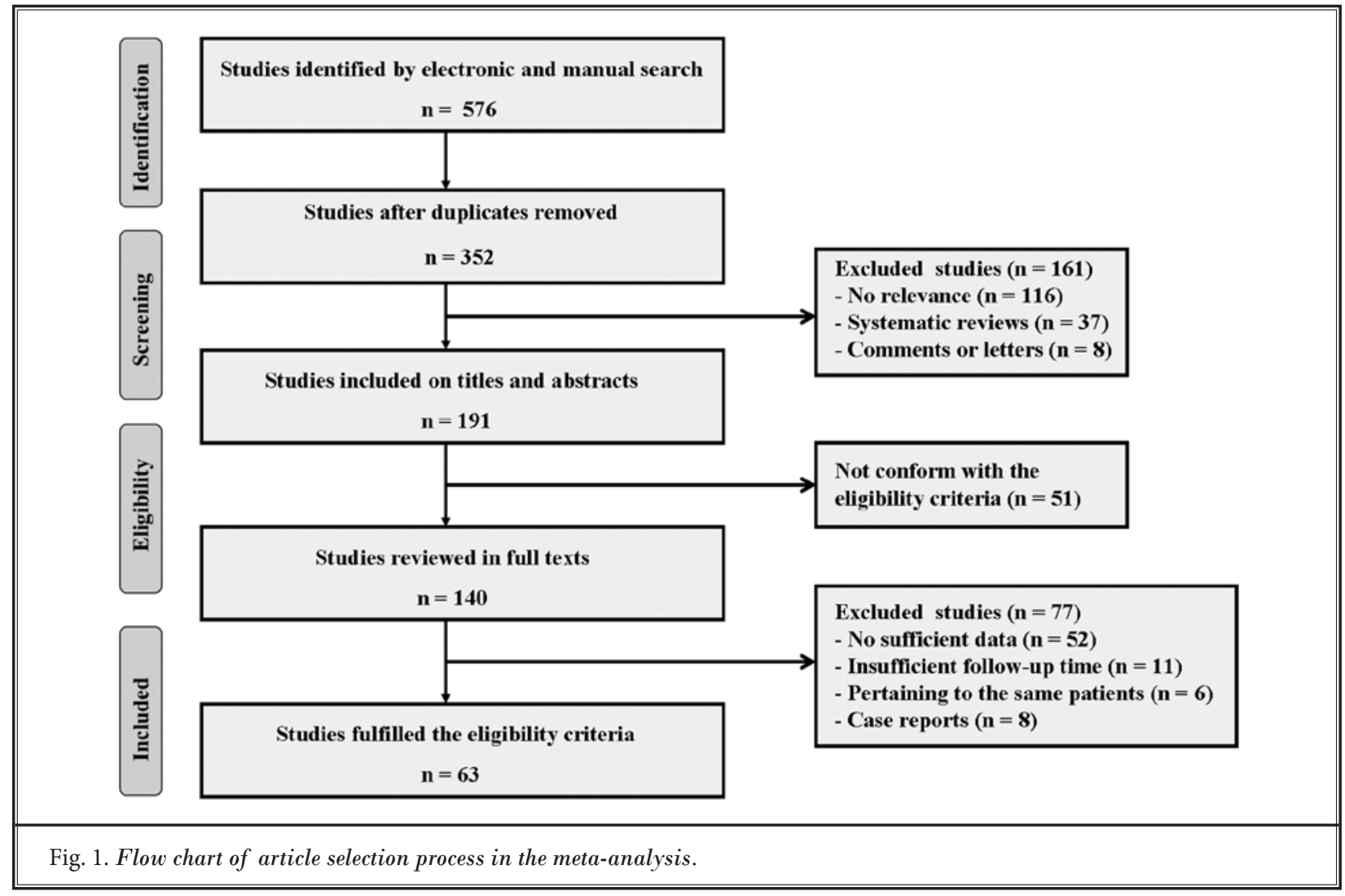


with apparent lack of relevance. Using the eligibility criteria, another 51 of the left 191 manuscripts were excluded after the full texts were reviewed. Furthermore, 77 articles were excluded for no sufficient data, insufficient follow-up time, and pertaining to the same patients, or only clinical case reports. The exclusions left 63 studies $(2,4-6,8,13-70)$ for the current review and meta-analysis, involving a total of 23,930 patients.

We recorded the characteristics and details of the clinical outcomes of the 63 included papers (Appendix 1). Fifteen studies were prospective (including 2 randomized controlled trials), and the remainder were retrospective. The sample size ranged from 16 to 10,228 with a median of 80 . The follow-up of all included studies ranged from 6 to 60 months. The mean age of patients at surgery ranged from 16.5 to 62.3 years. Most of the included articles were published in English except 2 manuscripts written in Chinese. Among all included studies, 34 articles were focused on recurrent herniations following PETD, while 12 articles focused on PEID. Partial studies mentioned the incidence of recurrent herniation after PELD in terms of age, BMI, recurrence time, the location, and type and level of herniated disc. All relevant information listed and other general characteristics of the included articles were recorded.

\section{Overall Prevalence of Recurrent Herniation after PELD}

Sixty-three studies of a total of 23,930 patients, including 470 patients with recurrent herniation after PELD, were included for the current study. The metaanalysis showed that the pooled prevalence of recurrent herniation by random effects model was 3.6\% (95\% $\mathrm{Cl} 3.0-4.3 \%)$, with substantial heterogeneity among included trials (Fig. 2). The recurrence rate among the studies varied between 0 and $12.5 \%$.

\section{Subgroup Meta-Analysis}

\section{Surgical Approach Related Recurrence}

Table 1 summarizes the stratified meta-analysis based on different surgical procedures including PETD and PEID. There was no significant difference between the pooled prevalence estimates of recurrent herniation after PEID $(4.2 \%, 95 \% \mathrm{Cl} 2.6-5.7 \%)$ and PETD (3.4\%, 95\% Cl 2.6-4.2\%).

\section{Age and Obesity Related Recurrence}

The results shown in Table 1 revealed that the pooled recurrence rate after PELD in older patients $(\geq$
50 years) was significantly higher than those who were younger ( $<50$ years) $(4.3 \%$ vs. $2.7 \%)$, and the lowest incidence of recurrence in older patients was almost the same as the peak incidence of recurrence in younger patients. Our meta-analysis also showed that the obese patient (BMI $\geq 25$ ) had an obviously higher (more than triple) prevalence estimate than those with normal BMI $(4.8 \%$ vs. $1.5 \%)$, and the pooled highest recurrence rate was $5.7 \%$ and $2.2 \%$, respectively.

\section{Herniated Disc Level Related Recurrence}

The levels of lumbar discs were divided into 3 categories that were upper disc (includes L1-2, L2-3, and L3-4), L4-5, and L5-S1, respectively. The results in Table 1 show that the prevalence of recurrent herniation at upper discs was significantly higher than that at L4-5 and L5-S1, with a highest incidence of $14.8 \%, 5.0 \%$ and $4.6 \%$, respectively. The pooled estimates of recurrence at L4-5 and L5-S1 were $2.7 \%(95 \% \mathrm{Cl} 0.3-5.0 \%)$ and $3.1 \%(95 \% \mathrm{Cl} 1.6-4.6 \%)$, with no significant differences detected.

\section{Herniated Disc Location and Type Related Recurrence}

Since there were too little data for recurrence focused on central and paramedian herniated disc, only prevalence of recurrent herniation at the lateral disc (including foraminal and extraforaminal disc) was pooled in our meta-analysis. The estimated recurrence rate at the lateral disc was slightly higher than the overall incidence of recurrence $(4.7 \%$ vs. $3.6 \%)$, but with no significant difference. The subgroup analysis also revealed that the recurrence rate of migrated herniation was $3.8 \%$ (95\% Cl $2.9-4.6 \%)$, which was comparable to the overall prevalence.

\section{Recurrence Time Related Incidence}

The pooled results showed that the early $(\leq 6$ months) recurrence rate after PELD was significantly higher than the later (> 6 months) recurrence rate $(2.1 \%$ vs. $1.2 \%)$, with a highest incidence of $2.9 \%$ and $1.9 \%$, respectively. Meanwhile, the early recurrence accounted for $61.7 \%$ of total recurrent herniations in included studies.

\section{Recurrence Rate With or Without Additional Procedure}

The results summarized in Table 1 suggested that the prevalence of recurrent herniation after PELD with foraminoplasty was $3.4 \%$, with a highest incidence of 


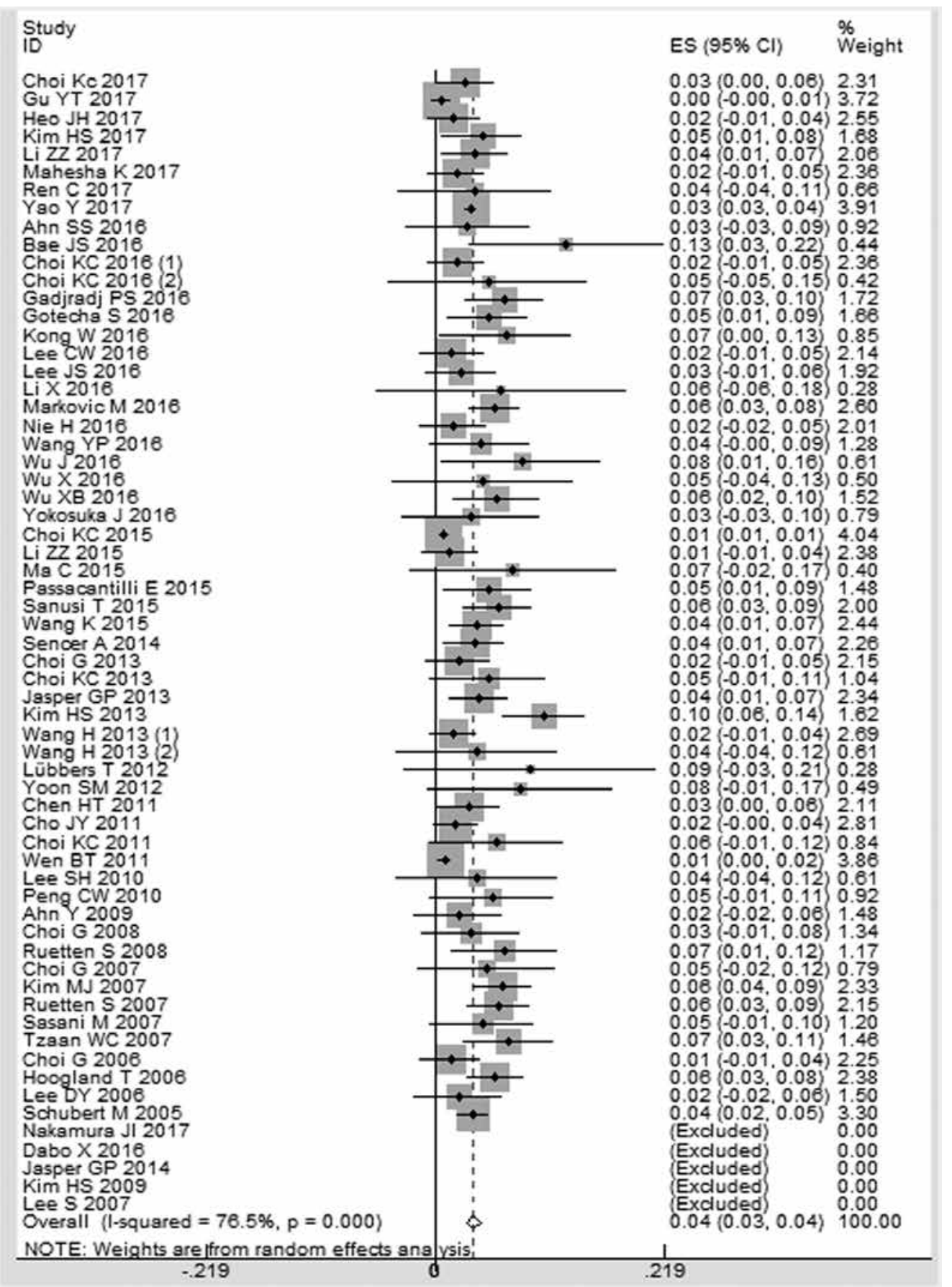

Fig. 2. Forest plot of the prevalence of recurrent herniation following PELD.

$4.5 \%$, which was comparable to the overall prevalence. For annular sealing, only one study reported a recurrence rate of $5.5 \%$, which was significantly lower than those without annular sealing (13.5\%).

\section{Sensitivity Analysis}

Sensitivity analysis was conducted to confirm the stability and liability of the meta-analysis by omitting the studies which may largely influence the clinical 
Table 1. Stratified meta-analysis of recurrence rate following PELD.

\begin{tabular}{|c|c|c|c|c|c|c|c|}
\hline \multirow[b]{2}{*}{ Subgroups } & \multirow[b]{2}{*}{ No. of trials } & \multirow{2}{*}{$\begin{array}{c}\text { No. of total } \\
\text { patients }\end{array}$} & \multirow{2}{*}{$\begin{array}{c}\text { No. of } \\
\text { recurrence }\end{array}$} & \multirow{2}{*}{$\begin{array}{c}\text { Pooled } \\
\text { recurrence rate } \\
(\%)\end{array}$} & \multirow[b]{2}{*}{$95 \%$ CI } & \multicolumn{2}{|c|}{ Heterogeneity } \\
\hline & & & & & & $\mathbf{I}^{2}(\%)$ & $Q$ test $P$ value \\
\hline \multicolumn{8}{|l|}{ Surgical procedure } \\
\hline PETD & 34 & 17591 & 354 & 3.4 & $2.6-4.2$ & 78.1 & $<0.001$ \\
\hline PEID & 12 & 1260 & 68 & 4.2 & $2.6-5.7$ & 45.6 & 0.043 \\
\hline \multicolumn{8}{|l|}{ Age (years) } \\
\hline$<50$ & 5 & 2076 & 57 & 2.7 & $2.0-3.4$ & 0 & 0.996 \\
\hline$\geq 50$ & 2 & 1612 & 70 & 4.3 & $3.3-5.3$ & 0 & 0.756 \\
\hline \multicolumn{8}{|l|}{ BMI } \\
\hline$<25$ & 2 & 1395 & 23 & 1.5 & $0.9-2.2$ & 60.2 & 0.113 \\
\hline$\geq 25$ & 3 & 2100 & 102 & 4.8 & $3.9-5.7$ & 0 & 0.452 \\
\hline \multicolumn{8}{|l|}{ Level of herniated disc } \\
\hline Upper disc & 3 & 102 & 5 & 5.4 & $0-14.8$ & 0 & 0.680 \\
\hline L4-5 & 4 & 624 & 14 & 2.7 & $0.3-5.0$ & 47.8 & 0.125 \\
\hline L5-S1 & 13 & 1179 & 49 & 3.1 & $1.6-4.6$ & 55.5 & 0.008 \\
\hline \multicolumn{8}{|l|}{ Special types } \\
\hline $\begin{array}{l}\text { Foraminal/ } \\
\text { extraforaminal }\end{array}$ & 4 & 158 & 8 & 4.7 & $1.4-8.0$ & 0 & 0.879 \\
\hline Migrated & 4 & 1946 & 73 & 3.8 & $2.9-4.6$ & 0 & 0.974 \\
\hline \multicolumn{8}{|l|}{ Recurrence time } \\
\hline Early ( $\leq 6$ months) & 18 & 1538 & 45 & 2.1 & $1.2-2.9$ & 22.7 & 0.185 \\
\hline Late (> 6 months) & 10 & 955 & 19 & 1.2 & $0.5-1.9$ & 0 & 0.530 \\
\hline With foraminoplasty & 6 & 1012 & 36 & 3.4 & $2.3-4.5$ & 0 & 0.885 \\
\hline Total & 63 & 20390 & 470 & 3.6 & $3.0-4.3$ & 76.5 & $<0.001$ \\
\hline
\end{tabular}

Abbreviation: $\mathrm{No}=$ number, $\mathrm{CI}=$ confidential interval, $\mathrm{PETD}=$ percutaneous endoscopic transforaminal discectomy, PEID = percutaneous endoscopic interlaminar discectomy, BMI = body mass index

results. We performed a series of sensitivity analysis by excluding 15 prospective studies, by excluding 21 studies with total patients $<50$ or $>500$, and by excluding 9 studies with period of follow-up less than 12 months, respectively. The pooled results showed that no single one had a remarkable influence on the overall prevalence. All the findings indicate the robustness of the results of our meta-analysis.

\section{Publication Bias}

According to the funnel plot (Fig. 3) and the result of Egger's regression test $(P=0.485)$, no obviously statistical evidence of publication bias was detected among the included studies. Likewise, the results of Egger's regression test for subgroup analysis revealed no significant publication bias in included studies (Table 3).

\section{Discussion}

To our knowledge, this is the most comprehensive and detailed meta-analysis focused on the prevalence estimates of recurrent herniation after PELD. The current meta-analysis involved a total of 20,390 patients and 63 studies from 13 countries and territories and the result showed that the overall prevalence of recurrent herniation after PELD was 3.6\%. No statistical evidence of publication bias was detected, and sensitivity analyses confirmed the robustness of the results of our metaanalysis (Table 2). Our review differs from previously published reviews (71-72) because it assesses the updated and full range of relevant trials with no or fewer restrictions related to the study design, language, and follow-up periods. Our pooled overall recurrence rate was slightly higher than that of $3.33 \%$ reported by Li X et al (71), who reviewed only 7 related articles dating up to September 2015. In the last 2 years, 27 reports referring to the recurrence after PELD have been published, so it is very necessary to update statistical data for obtaining accurate information. 
Funnel plot with pseudo $95 \%$ confidence limits

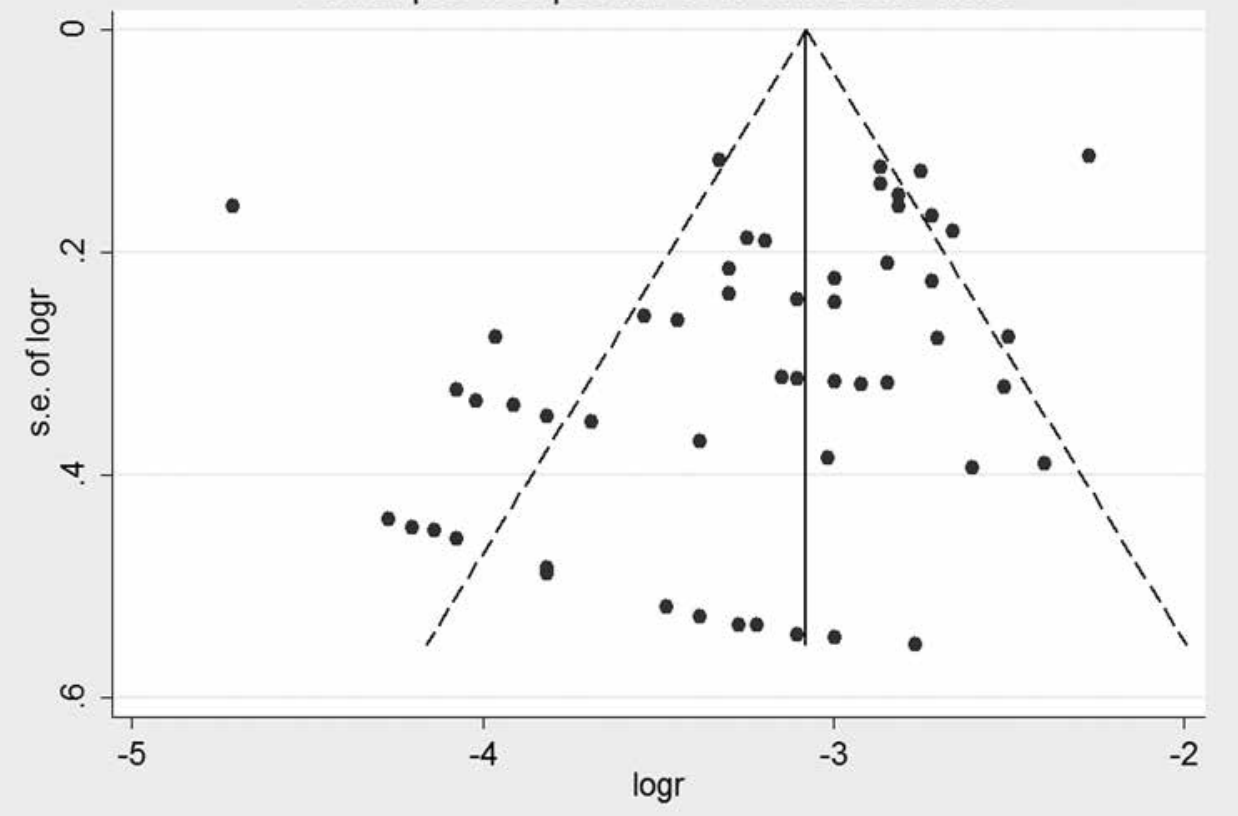

Fig. 3. Funnel plot of the included studies for prevalence of recurrent herniation following PELD.

Table 2. Sensitivity analysis of the rate of recurrence rate following PELD.

\begin{tabular}{|l|c|c|c|c|c|}
\hline \multicolumn{1}{|c|}{ Sensitivity analysis } & Remained studies & \multirow{2}{*}{$\begin{array}{c}\text { Pooled recurrence } \\
\text { rate (\%) }\end{array}$} & \multirow{2}{*}{ 95\% CI } & \multicolumn{2}{|c|}{ Heterogeneity } \\
\cline { 4 - 6 } $\mathbf{I}^{2}(\%)$ & Q test P value \\
\hline 1. Excluded studies that were prospective & 48 & 3.1 & $2.4-3.8$ & 76.2 & $<0.001$ \\
\hline $\begin{array}{l}\text { 2. Excluded studies with No. of total patients }<50 \\
\text { and }>500\end{array}$ & 42 & 3.8 & $3.0-4.6$ & 57.3 & $<0.001$ \\
\hline $\begin{array}{l}\text { 3. Excluded studies with period of follow-up }<12 \\
\text { months }\end{array}$ & 54 & 3.5 & $2.8-4.2$ & 77.1 & $<0.001$ \\
\hline
\end{tabular}

Abbreviation: $\mathrm{CI}=$ confidential interval, $\mathrm{No}=$ number

Another highlight of the present study is the subgroup analyses based on surgical procedure, age, BMI, recurrence time, the location, type and level of herniated disc, and additional procedures to investigate the prevalence of recurrence and confirm potential risk factors. Subgroup analysis by surgical procedure shows that the pooled recurrence rates following PETD and PEID were approximately equal. Although previous studies have not reached a consensus, most studies' conclusions were consistent with our result $(43,45,60)$.

It is generally accepted that old age and obesity are potential risk factors for recurrence after PELD (5$6,31,41)$. The finding of our meta-analysis reconfirmed that the prevalence of recurrent herniation after PELD was significantly higher in older ( $\geq 50$ years) and obese $(B M I \geq 25)$ patients. The conclusion is reasonable given that the older discs are often degenerative, and the remaining fragment of the nucleus pulposus is more susceptible to prolapse in response to mechanical overload, which was caused by annular incision during surgery (73). Likewise, excess weight with the cyclical increase of the intradiscal pressure could lead to higher shear strains in the posterolateral part of the annulus fibrosus, which would result in disc herniation (74-75).

Consistent with observations from previous studies $(32,57)$, the result of our meta-analysis suggests that the prevalence of recurrent herniation at upper disc is obviously higher than that at L4-5 and L5-S1. The 
Table 3. Publication bias analysis of the included studies for subgroup analysis.

\begin{tabular}{|c|c|}
\hline \multirow{2}{*}{ Subgroup analysis } & Egger's test \\
\hline & P value \\
\hline \multicolumn{2}{|l|}{ Surgical procedure } \\
\hline PETD & 0.969 \\
\hline PEID & 0.064 \\
\hline \multicolumn{2}{|l|}{ Age (years) } \\
\hline$<50$ & 0.221 \\
\hline$\geq 50$ & 0.317 \\
\hline \multicolumn{2}{|l|}{ BMI } \\
\hline$<25$ & 0.317 \\
\hline$\geq 25$ & 0.551 \\
\hline \multicolumn{2}{|l|}{ Herniation level } \\
\hline Upper discs & 0.208 \\
\hline L4-5 & 0.089 \\
\hline L5-S1 & 0.080 \\
\hline \multicolumn{2}{|l|}{ Special types } \\
\hline Foraminal/extraforaminal & 0.225 \\
\hline Migrated & 0.980 \\
\hline \multicolumn{2}{|l|}{ Recurrence time } \\
\hline Early ( $\leq 6$ months) & 0.105 \\
\hline Late (> 6 months) & 0.120 \\
\hline With foraminoplasty & 0.700 \\
\hline Total & 0.485 \\
\hline
\end{tabular}

Abbreviation: PETD = percutaneous endoscopic transforaminal discectomy, PEID = percutaneous endoscopic interlaminar discectomy, $\mathrm{BMI}=$ body mass index

definite reason remains unclear; however, it can be speculated that the unique anatomical environment of the upper lumbar level such as a smaller spinal canal, a larger dural sac, and conus medullaris in the dural sac, and the inherent technical difficulty might be the main reason for the high incidence of recurrence (76). On the other hand, the prevalence of recurrent herniation at L4-5 was comparable to that at L5-S1 level.

Owing to the paucity of pooled data, the subgroup analysis by the location and type of herniated disc was only conducted for the prevalence estimate of the recurrent herniation at the lateral disc and migrated disc. Neither of the estimated recurrence rates showed significant difference compared with the overall incidence of recurrence. However, only one large samplebased study by Yao $Y$ et al (6) reported a recurrence rate of $4.7 \%$ for the central disc herniation, which was significantly higher than that of paramedian herniation $(2.7 \%, P=0.008)$. One possible reason is that, for the treatment of central herniation with PETD approach, the working channel is placed inside the nucleus pulposus with a very steep trajectory angle. As a result, the ruptured intervertebral disc is not easily accessible, and the choice of working channel position may be the main cause of the high incidence of recurrence (36). Therefore, for central herniation, especially at the L5S1 level, the PEID approach might be the best option. Previous studies demonstrated that migrated herniation was a risk factor responsible for recurrence after $\operatorname{PELD}(7,33,59)$, given that the view of endoscopic surgery is limited, and it is difficult to remove the hidden fragments beyond the operation area (6). However, in this current study there was no significant increase in recurrence of migrated disc herniation compared with the overall estimate. This might indicate the patients benefited from the progress made in the endoscopic technique, especially in the last 10 years. The incomplete removal of the herniated fragment caused by the migrated herniations has been reduced.

According to the result of our meta-analysis, the incidence of early recurrence was nearly double the late recurrence rate, and patients with early recurrence account for the majority of patients with recurrent herniations. In other words, recurrence after PELD usually occurred within 6 months, which was consistent with observations from previous studies $(8,77)$. For additional procedures, the pooled result of subgroup analysis showed that there was no obvious difference between the recurrence rates after PELD with or without foraminoplasty. Kim et al (8) proposed a new technique of annular sealing after fragmentectomy to minimize the annular defects during PEID. The circumference of the annular fissure was coagulated by more than 10 times, using bipolar radiofrequency toward the annular defect. Radiofrequency was adjusted to 15 watts and coagulation duration was timed to less than one second per coagulation. After constriction, tightening and reduction of the annular fissure were observed. They reported that the PEID with annular sealing resulted in lower recurrence rate than without annular sealing (5.5\% vs. $2.7 \%, P=0.026)$.

Other probable predictive factors include gender, smoking, degenerated disc, the Modic changes, and learning curve of the surgeon, disputes remain. However, Kim et al (7) reported that the old age, higher BMI, the presence of the Modic changes and the protrusion increased the recurrence rates after successful PELD. Yao et al (6) also suggested that the older age, obesity, learning curve of the surgeon, treatment period, and 
central location of herniation were independently significant risk factors for recurrence after PELD. Likewise, Cinotti et al. (78) reported that those male patients with markedly degenerated discs could be risk factors for recurrent herniation after microdiscectomy. On the other hand, it was reported by Swartz that age, gender, smoking status, level of herniation and duration of symptoms were not associated with a higher rate of recurrence after partial laminectomy and discectomy (79).

Based on the results of our meta-analysis, some advice could be provided for the appropriate patient selection and surgical indication of PELD. Surgeons need to be more aware of the older, obese patients, and patients with upper lumbar disc herniation or central disc herniation when using the PELD procedure. However, with the PELD technique, experience can also affect the success of the surgery, and experienced surgeons and medical centers who are experienced with PELD, can expand the indications of PELD.

Readers should be aware of limitations in the literature and with our study, in particular. First, significant heterogeneity among studies was observed. As it is generally recognized that heterogeneity often exists in such meta-analyses of overall prevalence (80-81), we conducted subgroup analysis to explore the probable source of prevalence heterogeneity; however, none of them could sufficiently explain the heterogeneity. Sec- ondly, a majority of included articles were retrospective studies with relatively low quality of evidence. Furthermore, not all of the included studies were designed for the prevalence study. Not all of them provided detailed characteristics of patients with recurrent herniation; this may have led to the impreciseness of the pooled data. Thirdly, owing to the paucity of data focused on recurrence from included studies, many potentially predictive factors related subgroup analyses could not be conducted, which may have influenced the accuracy and comprehensiveness of our meta-analysis.

\section{Conclusion}

Our meta-analysis revealed that the overall pooled prevalence of recurrent herniation after PELD was $3.6 \%$, and recurrence usually occurred within 6 months postoperatively. Older age ( $\geq 50$ years), obesity (BMI $\geq$ 25), upper lumbar disc and central disc herniation may be independent risk factors for recurrence after PELD; however, different surgical approach (PETD or PEID), lateral disc, migrated disc and foraminoplasty did not affect the incidence of recurrent herniation. Considering the limitations mentioned above, future studies of high quality and large populations are needed to better evaluate the prevalence of recurrent herniation and related risk factors after PELD. 


\section{要

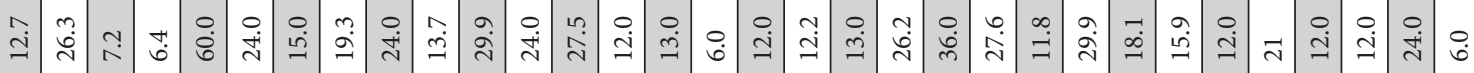

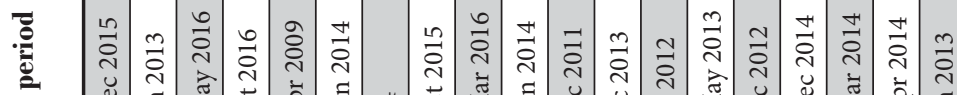

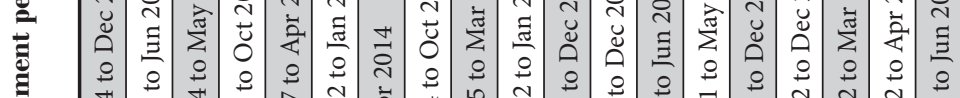

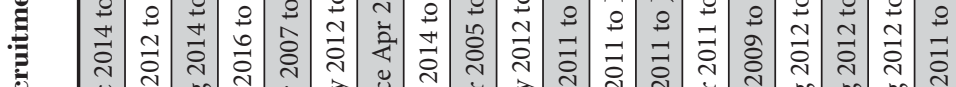

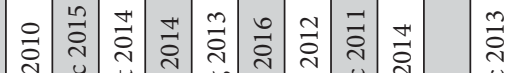 空

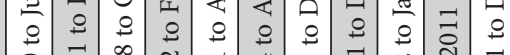 管 \\ 至

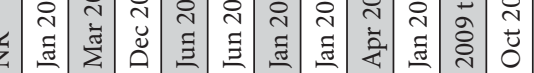

邹

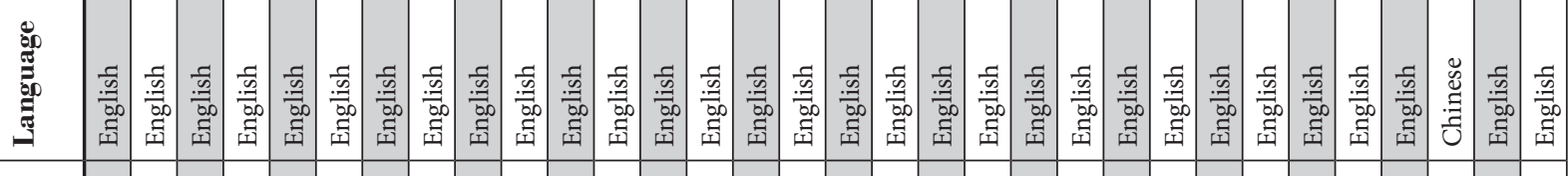 \\ चี

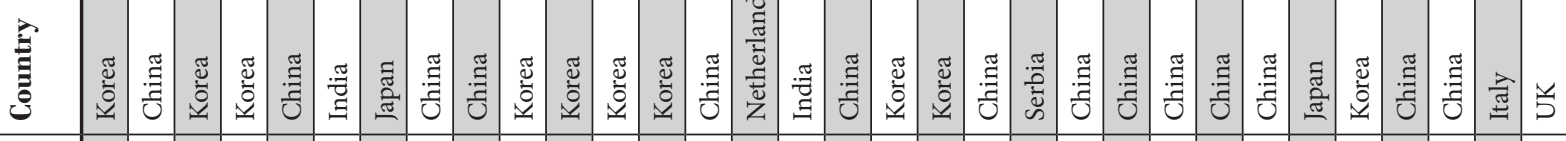

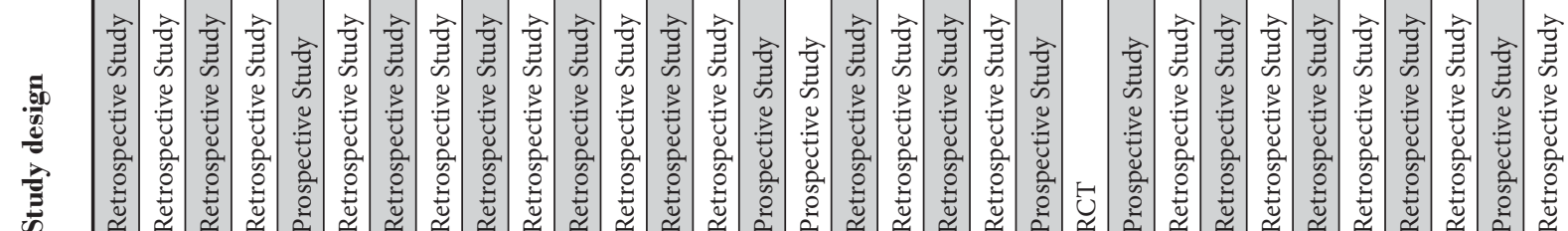

की

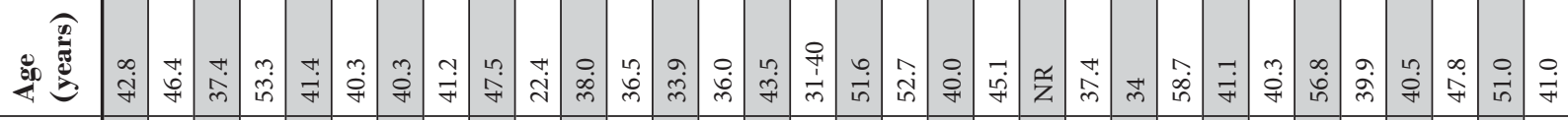
$\ddot{\theta}$

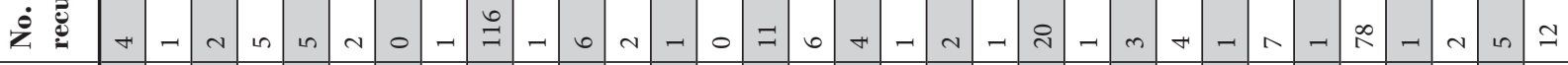

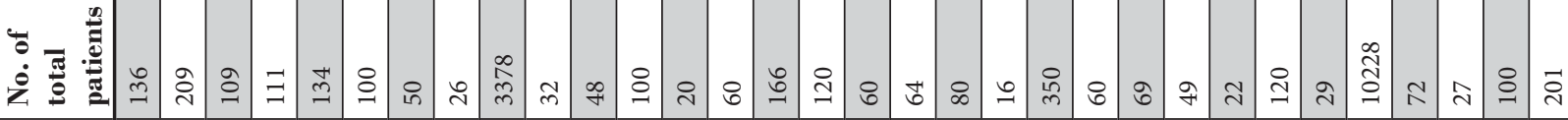

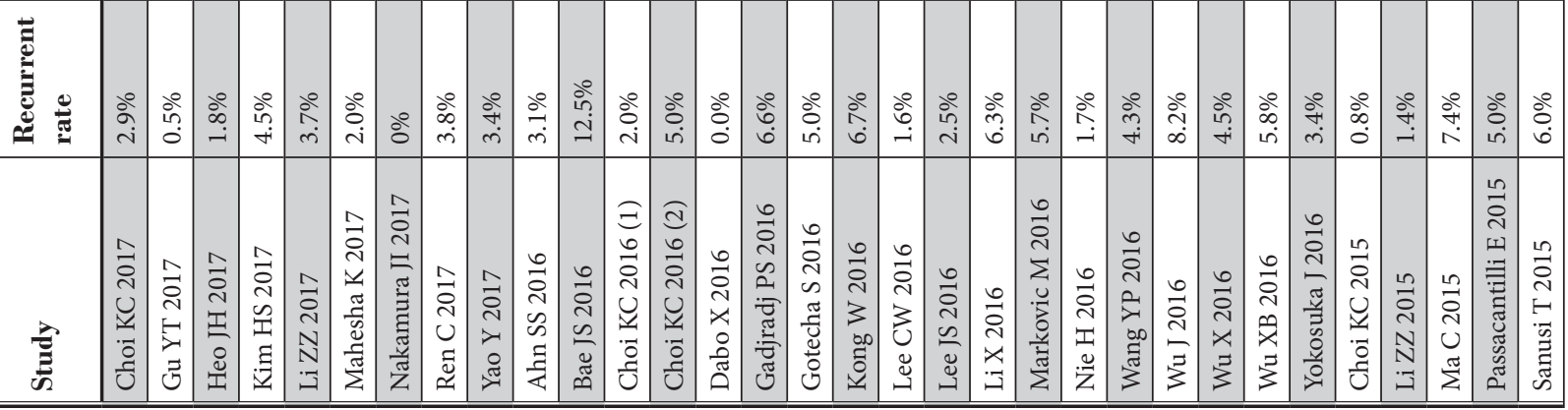




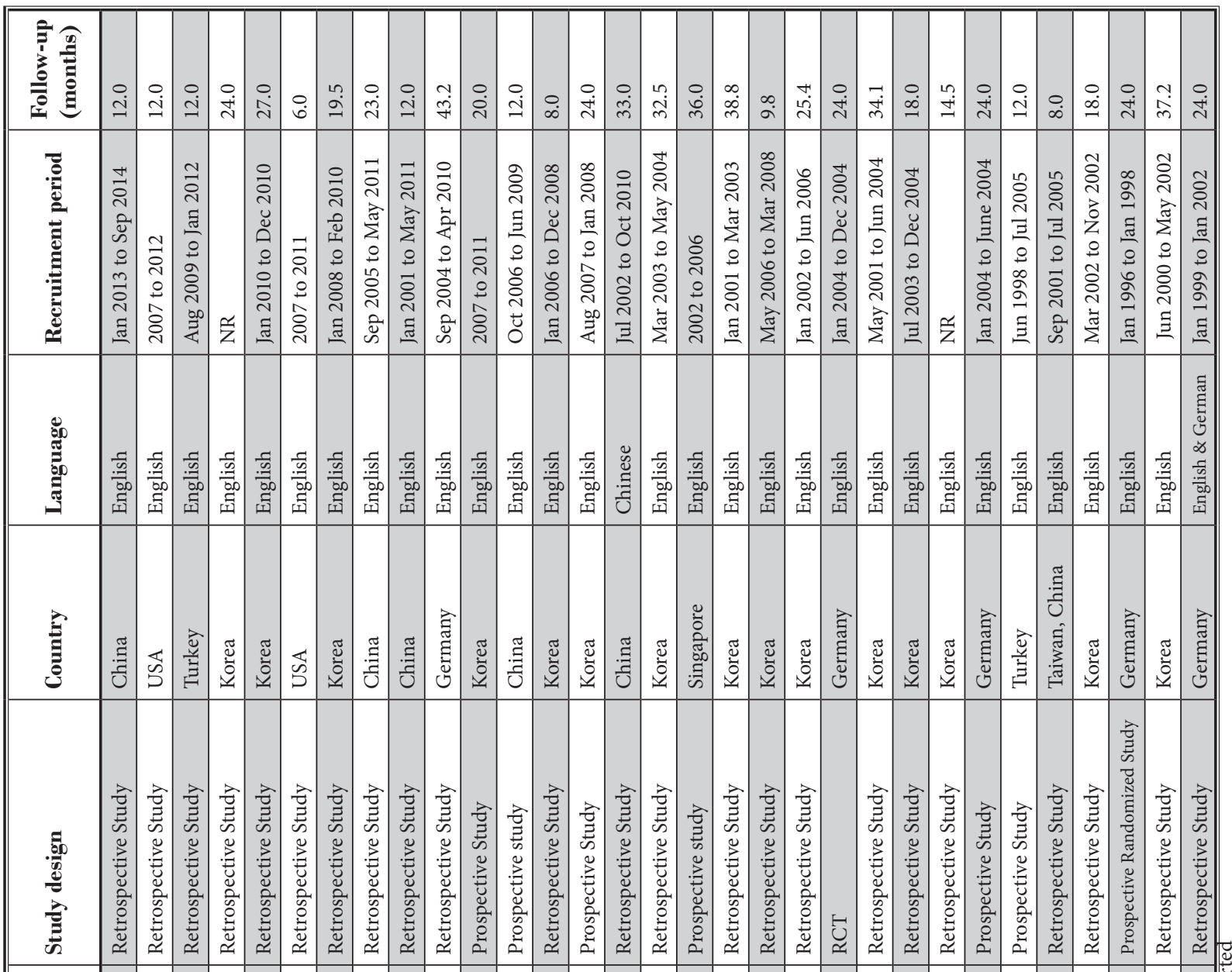

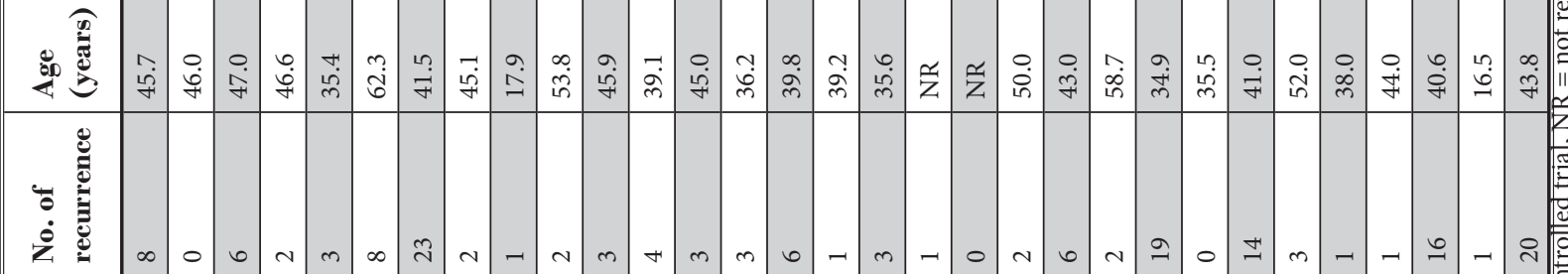

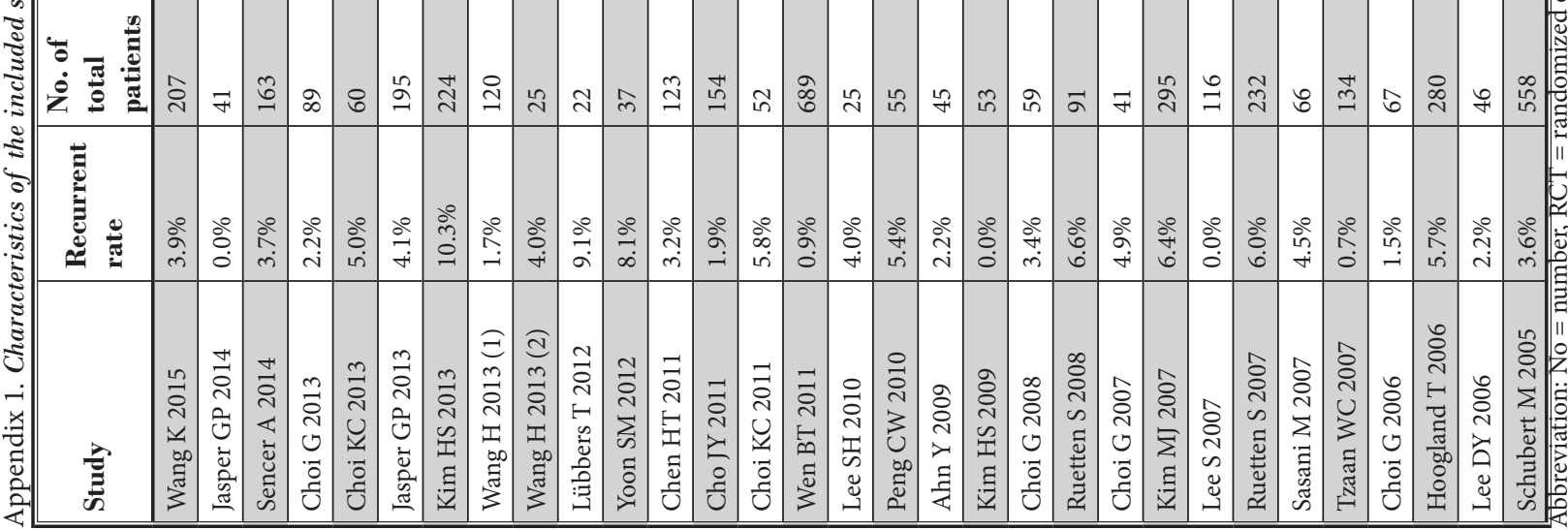




\section{References}

1. Eun SS, Lee SH, Sabal LA. Long-term follow-up results of percutaneous endoscopic lumbar discectomy. Pain Physician 2016; 19:E1161-E1166.

2. Nie H, Zeng J, Song Y, Chen G, Wang $X$, Li $Z$, Jiang $H$, Kong Q. Percutaneous endoscopic lumbar discectomy for $\mathrm{L}_{5}$-S 1 disc herniation via an interlaminar approach versus a transforaminal approach: A prospective randomized controlled study with 2-year followuUp. Spine (Phila Pa 1976) 2016; 41 Suppl 19:B30-B37.

3. Cheng J, Wang $H$, Zheng W, Li C, Wang J, Zhang Z, Huang B, Zhou Y. Reoperation after lumbar disc surgery in two hundred and seven patients. Int Orthop 2013; 37:1511-1517.

4. Nakamura JI, Yoshihara K. Initial clinical outcomes of percutaneous full-endoscopic lumbar discectomy using an interlaminar approach at the L4-L5. Pain Physician 2017; 20:E507-E512.

5. Bae JS, Lee SH. Transforaminal full-endoscopic lumbar discectomy in obese patients. Int J Spine Surg 2016; 10:18.

6. Yao $\mathrm{Y}$, Liu $\mathrm{H}$, Zhang $\mathrm{H}$, Wang $\mathrm{H}$, Zhang C, Zhang Z, Wu J, Tang Y, Zhou Y. Risk factors for recurrent herniation after percutaneous endoscopic lumbar discectomy. World Neurosurg 2017; 100:1-6.

7. Kim JM, Lee SH, Ahn Y, Yoon DH, Lee CD, Lim ST. Recurrence after successful percutaneous endoscopic lumbar discectomy. Minim Invasive Neurosurg 2007; 50:82-85.

8. Kim HS, Park JY. Comparative assessment of different percutaneous endoscopic interlaminar lumbar discectomy (PEID) techniques. Pain Physician 2013; 16:359-367.

9. Higgins JP, Thompson SG. Quantifying heterogeneity in a meta-analysis. Stat Med 2002; 21:1539-1558.

10. Huedo-Medina TB, Sánchez-Meca J, Marín-Martínez F, Botella J. Assessing heterogeneity in meta-analysis: $Q$ statistic or 12 index? Psychol Methods 2006; 11:193-206.

11. Trikalinos TA, Salanti G, Zintzaras E, loannidis JP. Meta-analysis methods. Adv Genet 2008; 60:311-334.

12. Egger M, Davey Smith G, Schneider M, Minder C. Bias in meta-analysis detected by a simple, graphical test. BM] 1997; 315:629-634.

13. Choi KC, Shim HK, Park C), Lee DC, Park CK. Usefulness of percutaneous endoscopic lumbar foraminoplasty for lumbar disc herniation. World Neurosurg 2017; pii: S1878-8750(17)31135-X. [Epub ahead of print]

14. Gu YT, Cui Z, Shao HW, Ye Y, Gu AQ. Percutaneous transforaminal endoscopic surgery (PTES) for symptomatic lumbar disc herniation: A surgical technique, outcome, and complications in 209 consecutive cases. J Orthop Surg Res 2017; 12:25.

15. Heo JH, Kim CH, Chung CK, Choi Y, Seo YG, Kim DH, Park SB, Moon JH, Heo W, Jung JM. Quantity of disc removal and radiological outcomes of percutaneous endoscopic lumbar discectomy. Pain Physician 2017; 20:E737-E746.

16. Kim HS, Yudoyono F, Paudel B, Kim KJ, Jang JS, Choi JH, Chung SK, Kim JH, Jang IT, Oh SH, Park JE, Lee S. Analysis of clinical results of three different routes of percutaneous endoscopic transforaminal lumbar discectomy for lumbar herniated disk. World Neurosurg 2017; 103:442-448.

17. Li ZZ, Hou SX, Shang WL, Song KR, Zhao HL. Modified percutaneous lumbar foraminoplasty and percutaneous endoscopic lumbar discectomy: Instrument design, technique notes, and 5 years follow-up. Pain Physician 2017; 20:E85-E98.

18. Mahesha K. Percutaneous endoscopic lumbar discectomy: Results of first 100 cases. Indian J Orthop 2017; 51:36-42.

19. Ren C, Li Y, Qin R, Sun P, Wang P. Transforaminal endoscopic lumbar discectomy for lumbar disc herniation causing bilateral symptoms. World Neurosurg 2017; pii: S1878-8750(17)31099-9. [Epub ahead of print]

20. Ahn SS, Kim SH, Kim DW, Lee BH. Comparison of outcomes of percutaneous endoscopic lumbar discectomy and open lumbar microdiscectomy for young adults: A retrospective matched cohort study. World Neurosurg 2016; 86:250-258.

21. Choi KC, Park CK. Percutaneous endoscopic lumbar discectomy for $\mathrm{L}_{5}$-S1 disc herniation: Consideration of the relation between the iliac crest and $\mathrm{L}_{5}-\mathrm{S}_{1}$ disc. Pain Physician 2016; 19:E301-E308.

22. Choi KC, Kim JS, Park CK. Percutaneous endoscopic lumbar discectomy as an alternative to open lumbar microdiscectomy for large lumbar disc herniation. Pain Physician 2016; 19:E291-E300.

23. Dabo X, Ziqiang C, Yinchuan Z, Haijian N, Kai C, Yanbin L, Qiang F, Chuanfeng $W$. The clinical results of percutane- ous endoscopic interlaminar discectomy (PEID) in the treatment of calcified lumbar disc herniation: A case-control study. Pain Physician 2016; 19:69-76.

24. Gadjradj PS, van Tulder MW, Dirven CM, Peul WC, Harhangi BS. Clinical outcomes after percutaneous transforaminal endoscopic discectomy for lumbar disc herniation: A prospective case series. Neurosurg Focus 2016; 40:E3.

25. Gotecha S, Ranade D, Patil SV, Chugh A, Kotecha M, Sharma S, Punia P. The role of transforaminal percutaneous endoscopic discectomy in lumbar disc herniations. J Craniovertebr Junction Spine 2016; 7:217-223.

26. Kong W, Liao W, Ao J, Cao G, Qin J, Cai $Y$. The strategy and early clinical outcome of percutaneous full-endoscopic interlaminar or extraforaminal approach for treatment of lumbar disc herniation. Biomed Res Int 2016; 4702946.

27. Lee CW, Yoon KJ, Ha SS, Kang JK. Foraminoplastic superior vertebral notch approach with reamers in percutaneous endoscopic lumbar discectomy: Technical note and clinical outcome in limited indications of percutaneous endoscopic lumbar discectomy. J Korean Neurosurg Soc 2016; 59:172-181.

28. Lee JS, Kim HS, Jang JS, Jang IT. Structural preservation percutaneous endoscopic lumbar interlaminar discectomy for $\mathrm{L}_{5}$-S1 herniated nucleus pulposus. Biomed Res Int 2016; 6250247.

29. Li X, Dou Q, Hu S, Liu J, Kong Q, Zeng J, Song Y. Treatment of cauda equina syndrome caused by lumbar disc herniation with percutaneous endoscopic lumbar discectomy. Acta Neurol Belg 2016; 116:185-190.

30. Markovic M, Zivkovic N, Spaic M, Gavrilovic A, Stojanovic D, Aleksic V, Ruetten S. Full-endoscopic interlaminar operations in lumbar compressive lesions surgery: Prospective study of 350 patients. "Endos" study. J Neurosurg Sci 2016; Jun 30. [Epub ahead of print]

31. Wang YP, Zhang W, An JL, Zhang J, Bai JY, Sun YP. Evaluation of transforaminal endoscopic discectomy in treatment of obese patients with lumbar disc herniation. Med Sci Monit 2016; 22:2513-2519.

32. Wu J, Zhang C, Zheng W, Hong CS, Li C, Zhou Y. Analysis of the characteristics and clinical outcomes of percutaneous endoscopic lumbar discectomy for upper lumbar disc herniation. World Neurosurg 2016; 92:142-147. 
33. Wu X, Fan G, Gu X, Guan X, He S. Surgical outcome of two-level transforaminal percutaneous endoscopic lumbar discectomy for far-migrated disc herniation. Biomed Res Int 2016; 4924013.

34. Wu XB, Fan GX, Gu X, Shen TG, Guan $X F$, Hu AN, Zhang HL, He SS. Learning curves of percutaneous endoscopic lumbar discectomy in transforaminal approach at the $L_{4} / 5$ and $L_{5} / S_{1}$ levels: $A$ comparative study. J Zhejiang Univ Sci B 2016; 17:553-560.

35. Yokosuka J, Oshima Y, Kaneko T, Takano $\mathrm{Y}$, Inanami H, Koga H. Advantages and disadvantages of posterolateral approach for percutaneous endoscopic lumbar discectomy. J Spine Surg 2016; 2:158-166.

36. Choi KC, Lee JH, Kim JS, Sabal LA, Lee S, Kim H, Lee SH. Unsuccessful percutaneous endoscopic lumbar discectomy: A single-center experience of 10,228 cases. Neurosurgery 2015; 76:372-380.

37. Li ZZ, Hou SX, Shang WL, Song KR, Zhao HL. The strategy and early clinical outcome of full-endoscopic L5/Sidiscectomy through interlaminar approach. Clin Neurol Neurosurg 2015; 133:40-45.

38. Ma C, Liu G, Xie L, Yang H, Gao J, Han M, Jiang X, Wan D, Liu L, Tang H. [Fullendoscopic interlaminar approach discectomy for central lumbar disc extrusion]. Zhonghua Yi Xue Za Zhi 2015; 95:1807-1810.

39. Passacantilli E, Lenzi J, Caporlingua F, Pescatori L, Lapadula G, Nardone A, Santoro A. Endoscopic interlaminar approach for intracanal $\mathrm{L}_{5}$-S 1 disc herniation: Classification of disc prolapse in relation to learning curve and surgical outcome. Asian J Endosc Surg 2015; 8:445-453

40. Sanusi T, Davis J, Nicassio N, Malik I. Endoscopic lumbar discectomy under local anesthesia may be an alternative to microdiscectomy: A single centre's experience using the far lateral approach Clin Neurol Neurosurg 2015; 139:324-327.

41. Wang K, Hong X, Zhou BY, Bao JP, Xie $X H$, Wang F, Wu XT. Evaluation of transforaminal endoscopic lumbar discectomy in the treatment of lumbar disc herniation. Int Orthop 2015; 39:1599-1604.

42. Jasper GP, Francisco GM, Telfeian A. Outpatient, awake, ultra-minimally invasive endoscopic treatment of lumbar disc herniations. R I Med J (2013) 2014; 97:47-49.

43. Sencer A, Yorukoglu AG, Akcakaya MO, Aras Y, Aydoseli A, Boyali O, Sencan F, Sabanci PA, Gomleksiz C, Imer M, Kiris
T, Hepgul K, Unal OF, Izgi N, Canbolat AT. Fully endoscopic interlaminar and transforaminal lumbar discectomy: Short-term clinical results of 163 surgically treated patients. World Neurosurg 2014; 82:884-89o.

44. Choi G, Modi HN, Prada N, Ahn TJ, Myung SH, Gang MS, Lee SH. Clinical results of XMR-assisted percutaneous transforaminal endoscopic lumbar discectomy. J Orthop Surg Res 2013; 8:14.

45. Choi KC, Kim JS, Ryu KS, Kang BU, Ahn $\mathrm{Y}$, Lee SH. Percutaneous endoscopic lumbar discectomy for $\mathrm{L}_{5}$-Si disc herniation: Transforaminal versus interlaminar approach. Pain Physician 2013; 16:547-556.

46. Jasper GP, Francisco GM, Telfeian AE. Clinical success of transforaminal endoscopic discectomy with foraminotomy: A retrospective evaluation. Clin Neurol Neurosurg 2013; 115:1961-1965.

47. Wang H, Huang B, Li C, Zhang Z, Wang J, Zheng W, Zhou Y. Learning curve for percutaneous endoscopic lumbar discectomy depending on the surgeon's training level of minimally invasive spine surgery. Clin Neurol Neurosurg 2013; 115:1987-1991.

48. Wang $\mathrm{H}$, Cheng J, Xiao H, Li C, Zhou Y. Adolescent lumbar disc herniation: Experience from a large minimally invasive treatment centre for lumbar degenerative disease in Chongqing, China. Clin Neurol Neurosurg 2013; 115:1415-1419.

49. Lübbers T, Abuamona R, Elsharkawy AE. Percutaneous endoscopic treatment of foraminal and extraforaminal disc herniation at the L5-S1 level. Acta Neurochir (Wien) 2012; 154:1789-1795.

50. Yoon SM, Ahn SS, Kim KH, Kim YD, Cho $\mathrm{JH}$, Kim DH. Comparative study of the outcomes of percutaneous endoscopic lumbar discectomy and microscopic lumbar discectomy using the tubular retractor system based on the VAS, ODI, and SF-36. Korean J Spine 2012; 9:215-222.

51. Chen HT, Tsai $\mathrm{CH}$, Chao SC, Kao TH, Chen YJ, Hsu HC, Shen CC, Tsou HK. Endoscopic discectomy of $\mathrm{L}_{5}-\mathrm{S}_{1}$ disc herniation via an interlaminar approach: Prospective controlled study under local and general anesthesia. Surg Neurol Int 2011; 2:93

52. Cho JY, Lee SH, Lee HY. Prevention of development of postoperative dysesthesia in transforaminal percutaneous endoscopic lumbar discectomy for intracanalicular lumbar disc herniation: Floating retraction technique. Minim In- vasive Neurosurg 2011; 54:214-218.

53. Choi KC, Kim JS, Kang BU, Lee CD, Lee $\mathrm{SH}$. Changes in back pain after percutaneous endoscopic lumbar discectomy and annuloplasty for lumbar disc herniation: A prospective study. Pain Med 2011; 12:1615-1621.

54. Wen BT, Zhang XF, Wang Y, Xiao SH, Liu ZS, Liu BW, Zhang YG, Song J, Zhong YX, Sun JH. [Complication and treatment of the lumbar intervertebral disc herniation using percutaneous endoscopic lumbar discectomy]. Zhonghua Wai Ke Za Zhi 2011; 49:1091-1095.

55. Lee SH, Kang HS, Choi G, Kong BJ, Ahn Y, Kim JS, Lee HY. Foraminoplastic ventral epidural approach for removal of extruded herniated fragment at the $\mathrm{L}_{5}$ Si level. Neurol Med Chir (Tokyo) 2010; 50:1074-1078.

56. Peng CW, Yeo W, Tan SB. Percutaneous endoscopic discectomy: Clinical results and how it affects the quality of life. J Spinal Disord Tech 2010; 23:425-430.

57. Ahn Y, Lee SH, Lee JH, Kim JU, Liu WC. Transforaminal percutaneous endoscopic lumbar discectomy for upper lumbar disc herniation: Clinical outcome, prognostic factors, and technical consideration. Acta Neurochir (Wien) 2009; 151:199-206.

58. Kim HS, Ju Cl, Kim SW, Kim JG. Endoscopic transforaminal suprapedicular approach in high grade inferior migrated lumbar disc herniation. J Korean Neurosurg Soc 2009; 45:67-73.

59. Choi G, Lee SH, Lokhande P, Kong BJ, Shim CS, Jung B, Kim JS. Percutaneous endoscopic approach for highly migrated intracanal disc herniations by foraminoplastic technique using rigid working channel endoscope. Spine (Phila Pa 1976) 2008; 33: E508-E515.

6o. Ruetten S, Komp M, Merk H, Godolias G. Full-endoscopic interlaminar and transforaminal lumbar discectomy versus conventional microsurgical technique: A prospective, randomized, controlled study. Spine (Phila Pa 1976) 2008; 33:931-939.

61. Choi G, Lee SH, Bhanot A, Raiturker PP, Chae YS. Percutaneous endoscopic discectomy for extraforaminal lumbar disc herniations: Extraforaminal targeted fragmentectomy technique using working channel endoscope. Spine (Phila Pa 1976) 2007; 32:E93-E99.

62. Kim MJ, Lee SH, Jung ES, Son BG, Choi ES, Shin JH, Sung JK, Chi YC. Targeted percutaneous transforaminal endoscopic diskectomy in 295 patients: Compari- 
son with results of microscopic diskectomy. Surg Neurol 2007; 68:623-631.

63. Lee S, Kim SK, Lee SH, Kim WJ, Choi WC, Choi G, Shin SW. Percutaneous endoscopic lumbar discectomy for migrated disc herniation: Classification of disc migration and surgical approaches. Eur Spine J 2007; 16:431-437.

64. Ruetten S, Komp M, Merk H, Godolias G. Use of newly developed instruments and endoscopes: Full-endoscopic resection of lumbar disc herniations via the interlaminar and lateral transforaminal approach. J Neurosurg Spine 2007; 6:521-530.

65. Sasani M, Ozer AF, Oktenoglu T, Canbulat N, Sarioglu AC. Percutaneous endoscopic discectomy for far lateral lumbar disc herniations: Prospective study and outcome of 66 patients. Minim Invasive Neurosurg 2007; 50:91-97.

66. Tzaan WC. Transforaminal percutaneous endoscopic lumbar discectomy. Chang Gung Med J 2007; 30:226-234.

67. Choi G, Lee SH, Raiturker PP, Lee S, Chae YS. Percutaneous endoscopic interlaminar discectomy for intracanalicular disc herniations at $\mathrm{L}_{5}-\mathrm{S}_{1}$ using a rigid working channel endoscope. Neurosurgery 2016; 58:ONS59-68.

68. Hoogland T, Schubert M, Miklitz B, Ramirez A. Transforaminal posterolateral endoscopic discectomy with or without the combination of a low-dose chymopapain: A prospective randomized study in 280 consecutive cases. Spine (Phila Pa 1976) 2006; 31:E890-E897.

69. Lee DY, Ahn Y, Lee SH. Percutaneous endoscopic lumbar discectomy for adolescent lumbar disc herniation: Surgical outcomes in 46 consecutive patients. Mt Sinai J Med 2006; 73:864-870.

70. Schubert M, Hoogland T. Endoscopic transforaminal nucleotomy with foraminoplasty for lumbar disk herniation. Oper Orthop Traumatol 2005; 17:641-661.

71. Li X, Han Y, Di Z, Cui J, Pan J, Yang M, Sun G, Tan J, Li L. Percutaneous endoscopic lumbar discectomy for lumbar disc herniation. J Clin Neurosci 2016; 33:19-27.

72. Rasouli MR, Rahimi-Movaghar V, Shokraneh F, Moradi-Lakeh M, Chou R. Minimally invasive discectomy versus microdiscectomy/open discectomy for symptomatic lumbar disc herniation. Cochrane Database Syst Rev 2014; (9):CDo10328.

73. Cinotti G, Gumina S, Giannicola G, Postacchini F. Contralateral recurrent lumbar disc herniation. Results of discectomy compared with those in primary herniation. Spine (Phila Pa 1976) 1999; 24:800-806.

74. Callaghan JP, McGill SM. Intervertebral disc herniation: Studies on a porcine model exposed to highly repetitive flexion/extension motion with compressive force. Clin Biomech (Bristol, Avon) 2001; 16:28-37.
75. Schmidt H, Kettler A, Heuer F, Simon U, Claes L, Wilke HJ. Intradiscal pressure, shear strain, and fiber strain in the intervertebral disc under combined loading. Spine (Phila Pa 1976) 2007; 32:748-755.

76. Ido K, Shimizu K, Tada H, Matsuda Y, Shikata J, Nakamura T. Considerations for surgical treatment of patients with upper lumbar disc herniations. J Spinal Disord 1998; 11:75-79.

77. Lee SH, Kang BU, Ahn Y, Choi G, Choi YG, Ahn KU, Shin SW, Kang HY. Operative failure of percutaneous endoscopic lumbar discectomy: A radiologic analysis of 55 cases. Spine (Phila Pa 1976) 2006; 31:E285-E290.

78. Cinotti G, Roysam GS, Eisenstein SM, Postacchini F. Ipsilateral recurrent lumbar disc herniation. A prospective, controlled study. J Bone Joint Surg $\mathrm{Br} 1998$; $80: 825-832$.

79. Swartz KR, Trost GR. Recurrent lumbar disc herniation. Neurosurg Focus 2003; 15: E3.

8o. Sharma S, Wu C, Andersen T, Wang Y, Hansen ES, Bünger CE. Prevalence of complications in neuromuscular scoliosis surgery: A literature meta-analysis from the past 15 years. Eur Spine J 2013; 22:1230-1249.

81. Xia XP, Chen HL, Cheng HB. Prevalence of adjacent segment degeneration after spine surgery: A systematic review and meta-analysis. Spine (Phila Pa 1976) 2013; 38:597-608. 